\title{
Tarlov Cyst Rupture and Intradural Hemorrhage Mimicking Intraspinal Carcinomatosis
}

\author{
Tejaswi Sudhakar ${ }^{1}$, Likowsky L. Désir ${ }^{2,1}$, Jason A. Ellis ${ }^{1}$ \\ 1. Neurosurgery, Lenox Hill Hospital Northwell Health, New York, USA 2. Medicine, City University of New York School \\ of Medicine, New York, USA
}

Corresponding author: Jason A. Ellis, jellis2@northwell.edu

\begin{abstract}
Lumbosacral Tarlov cysts (TCs) have rarely been seen to rupture. Here, we report an unusual presentation of a ruptured TC with intraspinal hemorrhage mimicking carcinomatosis. Pathological diagnosis was obtained using percutaneous biopsy. A conservative approach was utilized and an excellent outcome was achieved. Thus, in cases such as this, a ruptured hemorrhagic TC should be on the differential diagnosis to drive appropriate clinical management decisions.
\end{abstract}

Categories: Neurology, Neurosurgery, Oncology

Keywords: perineural cyst, spine hemorrhage, intradural tumor, leptomeningeal carcinoma, tarlov cyst

\section{Introduction}

Tarlov cysts (TCs), also known as perineural cysts, are spinal intradural cerebrospinal fluid (CSF)-filled sacs that form within the nerve root sleeves. These lesions are often found in the sacral region of the spinal column. Though predominantly asymptomatic, TCs may compress spinal nerve roots and clinically present with low back or leg pain and radiculopathy $[1,2]$. To our knowledge, hemorrhagic presentation of a ruptured TC mimicking carcinomatosis has not been previously reported. Here, we present such a case and detail our conservative management strategy.

\section{Case Presentation}

A 71-year-old woman with no significant past medical history presented with acute-onset headache, severe low back pain, and urinary retention. Physical examination was notable for sacrococcygeal tenderness to palpation and pain-limited antigravity motor strength in the legs. Head imaging was unremarkable. Lumbosacral MRI demonstrated a $3 \mathrm{~cm}$ heterogeneously enhancing mass-like lesion at the S3-S4 level. Additionally, diffuse cauda equina nerve root and leptomeningeal enhancement were noted (Figure 1, red arrow). A preliminary diagnosis of leptomeningeal carcinomatosis was rendered based on the imaging profile. A CT-guided needle biopsy of the sacral mass was performed, revealing organized hematoma and no evidence of malignant tissue. With this histological result, a decision was made to pursue conservative management, especially as the patient had progressive clinical improvement after the presentation. The patient was neurologically intact at the six-month follow-up. MRI at that time demonstrated complete resolution of the intraspinal hemorrhage and enhancement. Continued expansion of the sacral spinal canal and cystic dilation of the nerve root sleeves were indicating TC (Figure 2). 


\section{Cureus}

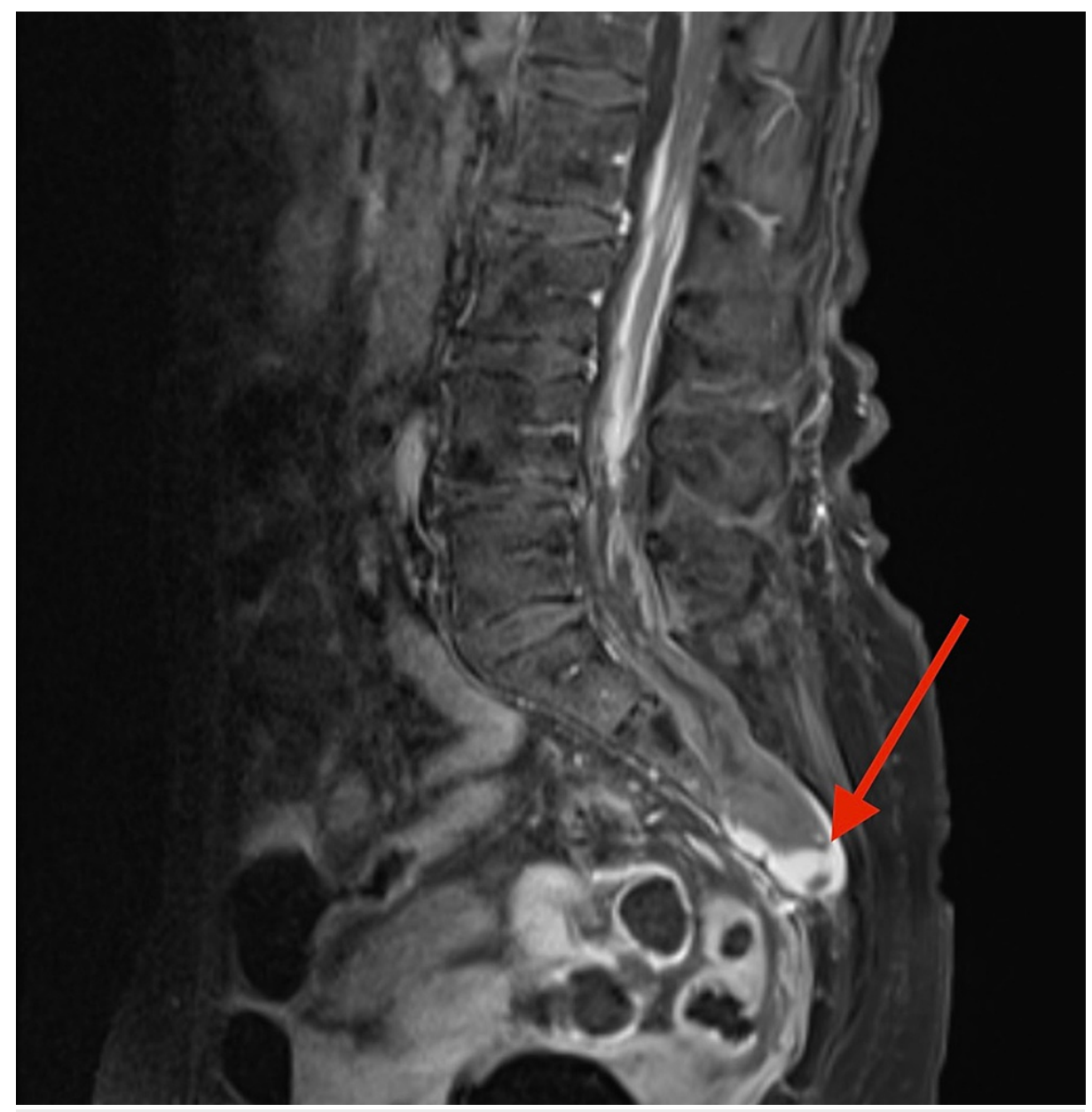

FIGURE 1: Sagittal T1 -weighted MRI with contrast revealing a high signal intensity $3 \mathrm{~cm}$ cystic lesion in the lumbosacral spine at S3-S4. Red arrow points to the lesion. 


\section{Cureus}

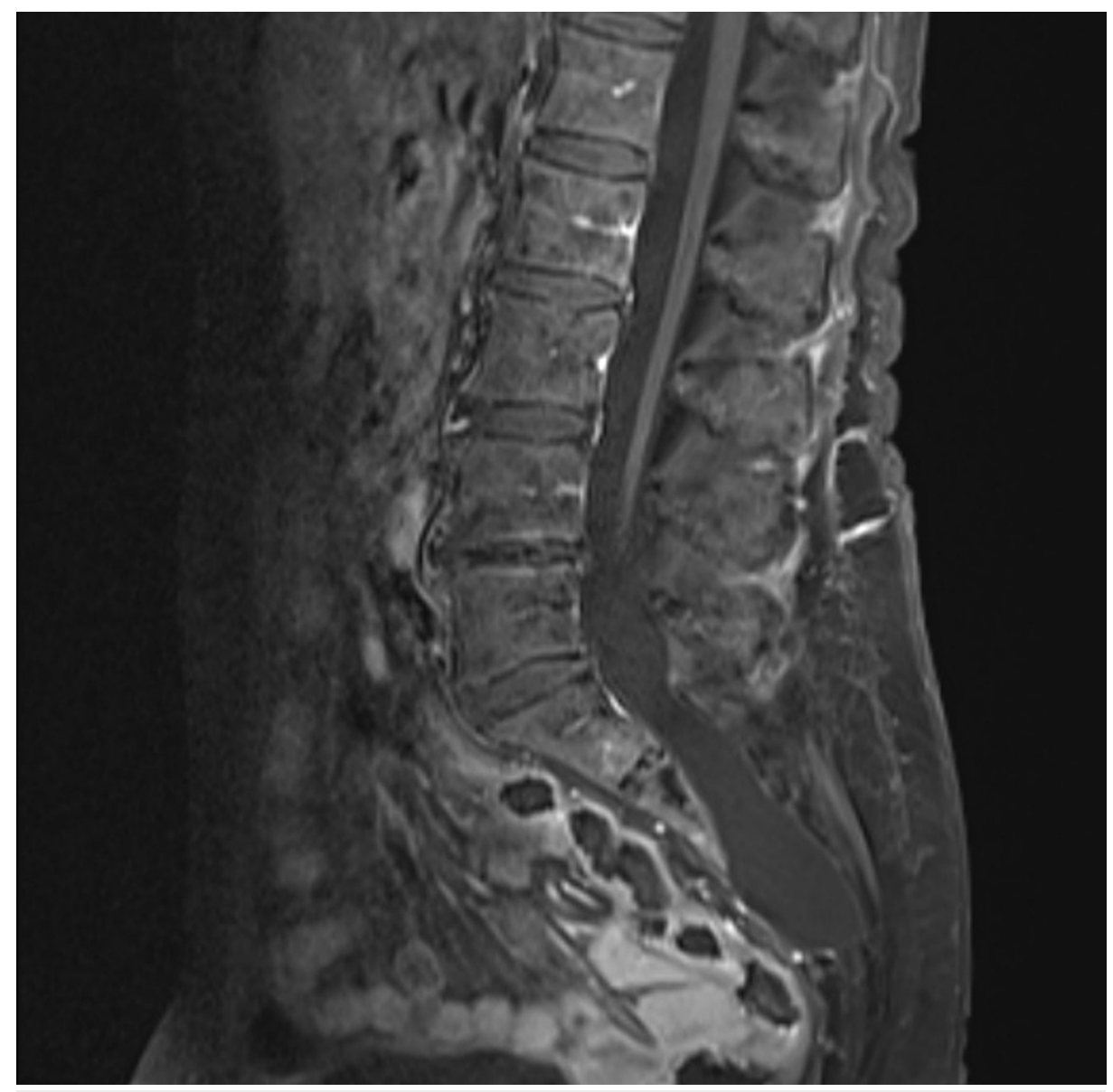

FIGURE 2: Postoperative six-month follow-up. Sagittal T1-weighted MRI with contrast revealing complete resolution of the intraspinal hemorrhage, with expansion of the sacral spinal canal and cystic dilation.

\section{Discussion}

TCs, or perineural cysts, are intradural CSF-filled sacs found within the lumbosacral spine [3]. They arise at or just distal to the dorsal root ganglion between the layers of the endo- and perineurium [4-10]. The incidence of TC is estimated to be between $1.5 \%$ and $4.6 \%$ with a prevalence of approximately $13 \%$ [11-13]. Kuhn et al. reported a $13.2 \%$ detection frequency of perineural cysts in 1,100 consecutive sacral MRI studies [14]. TCs are reported to be present in $4.0 \%$ of people less than 50 years old and in $1.3 \%$ of people greater than 50 years old [3]. Although the literature is not definitive, case reports and series suggest a female preponderance $[3,7,8,10-13,15-18]$.

TCs are most commonly asymptomatic and are generally found incidentally during radiographic studies performed for other reasons. Symptomatic TCs have a reported incidence of $1 \%$ in the adult population $[11,12,19]$. Enlarging TCs become symptomatic due to compression of the adjacent bone, perineural vasculature, or nerve fibers [20]. It has been proposed that TCs lacking significant communication with the subarachnoid space are more likely to be asymptomatic [15]. The etiology of TCs remains unclear although one theory proposes that stenosis at the ostium of the nerve root sleeve allows CSF influx with arterial systolic pulsation coupled with restricted outflow $[9,11,12,19]$. Myelographic demonstration of subarachnoid microcommunication supports a valve mechanism and differentiates TCs from other cystic osteolytic lesions within the lumbosacral space [18]. Surgical intervention is not indicated for the majority of symptomatic and asymptomatic TCs. Alternatively, percutaneous cyst drainage, fibrin glue injection, insertion of cystsubarachnoid or lumboperitoneal shunts, laser ablation, duraplasty, and microsurgical fenestration have been advocated in select cases [8,14].

Acute symptomatic presentation with cyst rupture and hemorrhage as seen in this case is quite rare. Godel et al. reported a case of a 38-year-old woman who developed acute radiculopathy in such a case [20]. Yates et al. reported the case of a 61-year-old man who developed symptomatic nerve root compression associated with cyst rupture [5]. Both cases resolved spontaneously without the need for surgical intervention. As seen 
in our case, complicated TCs can mimic intraspinal neoplasia in both clinical and radiographic findings. One report by Attiah et al. presented the case of a giant sacral schwannoma mimicking a TC [16].

\section{Conclusions}

TC rupture resulting in symptomatic intraspinal hemorrhage is rare. The possibility of symptomatic TCs merits a high degree of suspicion, especially if radiographic findings are suggestive of a neoplastic etiology. Conservative management is indicated in such a setting where TC is suspected, including cautious monitoring for clinical deterioration.

\section{Additional Information \\ Disclosures}

Human subjects: Consent was obtained or waived by all participants in this study. Conflicts of interest: In compliance with the ICMJE uniform disclosure form, all authors declare the following: Payment/services info: All authors have declared that no financial support was received from any organization for the submitted work. Financial relationships: All authors have declared that they have no financial relationships at present or within the previous three years with any organizations that might have an interest in the submitted work. Other relationships: All authors have declared that there are no other relationships or activities that could appear to have influenced the submitted work.

\section{References}

1. Murphy K, Oaklander AL, Elias G, Kathuria S, Long DM: Treatment of 213 patients with symptomatic Tarlov cysts by CT-guided percutaneous injection of fibrin sealant. AJNR Am J Neuroradiol. 2016, 37:373-9. 10.3174/ajnr.A4517

2. Beall DP, Googe DJ, Emery RL, et al.: Extramedullary intradural spinal tumors: a pictorial review . Curr Probl Diagn Radiol. 2007, 36:185-98. 10.1067/j.cpradiol.2006.12.002

3. Lucantoni C, Than KD, Wang AC, Valdivia-Valdivia JM, Maher CO, La Marca F, Park P: Tarlov cysts: a controversial lesion of the sacral spine. Neurosurg Focus. 2011, 31:E14. 10.3171/2011.9.FOCUS11221

4. Ahmadi F, Akhbari F: Adnexal masses or perineural (Tarlov) cysts? Differentiation by imaging techniques: a case report. Int J Reprod Biomed. 2017, 15:589-92.

5. Yates JR, Jones CS, Stokes OM, Hutton M: Incomplete cauda equina syndrome secondary to haemorrhage within a Tarlov cyst. BMJ Case Rep. 2017, 2017:bcr2017219890. 10.1136/bcr-2017-219890

6. Gungor S, Ozcan A: Management of lumbar radiculopathy due to disc herniation with interlaminar epidura steroid injection in the presence of multilevel Tarlov cysts in the neural foramina: a case report. Medicine (Baltimore). 2018, 97:e12389. 10.1097/MD.0000000000012389

7. Andrieux C, Poglia P, Laudato P: Tarlov cyst: a diagnostic of exclusion . Int J Surg Case Rep. 2017, 39:25-8. 10.1016/j.ijscr.2017.07.045

8. Burke JF, Thawani JP, Berger I, et al.: Microsurgical treatment of sacral perineural (Tarlov) cysts: case series and review of the literature. J Neurosurg Spine. 2016, 24:700-7. 10.3171/2015.9.SPINE153

9. Hain KS, Pickhardt PJ, Lubner MG, Menias CO, Bhalla S: Presacral masses: multimodality imaging of a multidisciplinary space. Radiographics. 2013, 33:1145-67. 10.1148/rg.334115171

10. Tsitsopoulos PP, Marklund N, Salci K, Holtz A, Mani M: Management of symptomatic sacral perineural cysts with microsurgery and a vascularized fasciocutaneous flap. J Spine Surg. 2018, 4:602-9. 10.21037/jss.2018.07.02

11. Yang AI, McShane BJ, Welch WC: Growth of a sacral perineural (Tarlov) cyst: clinical images . World Neurosurg. 2018, 119:400-1. 10.1016/i.wneu.2018.07.279

12. Yang AI, Rinehart CD, McShane BJ, Hitti FL, Welch WC: Growth of lumbosacral perineural (Tarlov) cysts: a natural history analysis. Neurosurgery. 2020, 86:88-92. 10.1093/neuros/nyy586

13. Liu B, Wang Z, Lin G, Zhang J: Radiculoplasty with reconstruction using 3D-printed artificial dura mater for the treatment of symptomatic sacral canal cysts: two case reports. Medicine (Baltimore). 2018, 97:e13289. 10.1097/MD.0000000000013289

14. Kuhn FP, Hammoud S, Lefèvre-Colau MM, Poiraudeau S, Feydy A: Prevalence of simple and complex sacral perineural Tarlov cysts in a French cohort of adults and children. J Neuroradiol. 2017, 44:38-43. 10.1016/j.neurad.2016.09.006

15. Ostojic P: Sacral perineural cyst mimicking inflammatory low back pain . Z Rheumatol. 2015, 74:75-7. 10.1007/s00393-014-1507-8

16. Attiah MA, Syre PP, Pierce J, Belyaeva E, Welch WC: Giant cystic sacral schwannoma mimicking tarlov cyst: a case report. Eur Spine J. 2016, 25 Suppl 1:84-8. 10.1007/s00586-015-4128-2

17. Caspar W, Papavero L, Nabhan A, Loew C, Ahlhelm F: Microsurgical excision of symptomatic sacral perineurial cysts: a study of 15 cases. Surg Neurol. 2003, 59:101-5. 10.1016/s0090-3019(02)00981-3

18. Neulen A, Kantelhardt SR, Pilgram-Pastor SM, Metz I, Rohde V, Giese A: Microsurgical fenestration of perineural cysts to the thecal sac at the level of the distal dural sleeve. Acta Neurochir (Wien). 2011, 153:1427-34. 10.1007/s00701-011-1043-0

19. Tanaka M, Nakahara S, Ito Y, Nakanishi K, Sugimoto Y, Ikuma H, Ozaki T: Surgical results of sacral perineural (Tarlov) cysts. Acta Med Okayama. 2006, 60:65-70. 10.18926/AMO/30758

20. Godel T, Pham M, Wolff M, Bendszus M, Bäumer P: Tarlov cyst hemorrhage causing acute radiculopathy: a case report. Clin Neuroradiol. 2018, 28:123-5. 10.1007/s00062-017-0597-5 